\title{
Variegated Squirrel Bornavirus 1 in Squirrels, Germany and the Netherlands
}

\author{
Kore Schlottau, Maria Jenckel, \\ Judith van den Brand, Christine Fast, \\ Christiane Herden, Dirk Höper, \\ Timo Homeier-Bachmann, Jens Thielebein, \\ Niels Mensing, Bert Diender, Donata Hoffmann, \\ Rainer G. Ulrich, Thomas C. Mettenleiter, \\ Marion Koopmans, Dennis Tappe, \\ Jonas Schmidt-Chanasit, Chantal B.E.M. Reusken, \\ Martin Beer, Bernd Hoffmann
}

We screened squirrels in Germany and the Netherlands for the novel zoonotic variegated squirrel bornavirus 1 (VSBV1). The detection of VSBV-1 in 11 squirrels indicates a considerable risk for transmission to humans handling those animals. Therefore, squirrels in contact with humans should routinely be tested for VSBV-1.

$\mathrm{T}$ e family Bornaviridae comprises the classical mammalian bornaviruses (Mammalian 1 bornavirus with borna disease virus; BoDV-1 and -2); avian bornaviruses (Passeriform 1/2 bornavirus, Psittaciform 1/2 bornavirus, Waterbird 1 bornavirus); and a recently described Elapid 1 bornavirus from snakes (Loveridge's garter snake virus 1) (1). BoDV-1 and -2 are considered nonzoonotic $(6-8)$. The bicolored white-toothed shrew (Crocidura leucodon) has been proposed as a reservoir species for BoDV-1 (2-5). In addition to the exogenous viruses, endogenous bornaviruslike genomic elements have been found within the genome of humans and several animal species, including the 13-lined ground squirrel (Spermophilus tridecemlineatus) $(9,10)$.

In 2015, a novel zoonotic bornavirus, the variegated squirrel bornavirus 1 (VSBV-1; new species Mammalian

Author affiliations: Friedrich-Loeffler-Institut, Greifswald-Insel Riems, Germany (K. Schlottau, M. Jenckel, C. Fast, D. Höper, T. Homeier-Bachmann, D. Hoffmann, R.G. Ulrich,

T.C. Mettenleiter, M. Beer, B. Hoffmann); Erasmus Medical Center, Rotterdam, the Netherlands (J. van den Brand, M. Koopmans, C.B.E.M. Reusken); Justus-Liebig University Gießen, Gießen, Germany (C. Herden); Martin Luther University Halle-Wittenberg, Halle, Germany (J. Thielebein); Tierarztpraxis Dr. Niels Mensing, Magdeburg, Germany (N. Mensing); Dierenartspraktijk Diender, Vlissingen, the Netherlands (B. Diender); Bernhard Nocht Institute for Tropical Medicine, Hamburg, Germany (D. Tappe, J. Schmidt-Chanasit)

DOI: http://dx.doi.org/10.3201/eid2303.161061
2 bornavirus), was discovered in tissue samples from the central nervous system (CNS) of 3 persons with encephalitis, which resulted in death (11). The patients were breeders of variegated squirrels (Sciurus variegatoides), and an almost identical bornavirus sequence was detected in 1 contact squirrel kept by one of the breeders. Phylogenetic analysis classified VSBV-1 as a unique member of a new species of the genus Bornavirus (11).

We identified more VSBV-1 infected squirrels in Germany and the Netherlands. We also describe reliable molecular and serologic methods for in vivo detection of zoonotic VSBV-1 and its phylogenetic characterization.

\section{The Study}

During 2015, samples were collected from 468 squirrels representing 14 species. Sampled squirrels were from varying locations: private holdings with up to 45 animals per holding, zoological gardens, or roadkill (Table 1). Locations represented 3 countries: Germany (399 samples from 28 holdings), the Netherlands (49 samples from 4 holdings), and the United Kingdom (20 samples from roadkill). Most live squirrels were sampled at the request of the owners. At least 1 swab sample and, if possible, duplicates of oral swab samples were collected from living animals, and brain samples were tested from dead squirrels. Blood samples (EDTA/heparin) were also available from 164 squirrels (Table 1). We obtained congruent results when we tested swabs and brain samples by 2 different VSBV-1-specific quantitative reverse transcription PCR (qRT-PCR) assays (11). Blood samples were centrifuged, and the resulting plasma was tested for the presence of viral RNA by using qRT-PCR and for bornavirus-specific IgG by using an indirect immunofluorescence assay (11).

We detected VSBV-1 RNA and bornavirus-specific antibodies in $11(2.6 \%)$ of the 468 animals. These 11 VSBV-1-positive squirrels ( 7 male, 4 female) belonged to the family Sciuridae, subfamilies Sciurinae (variegated squirrels, $S$. variegatoides; 6 animals) or Callosciurinae (Prevost's squirrel, C. prevostii; 5 animals) (Table 1). None of the animals showed clinical signs associated with CNS disorders. Of the 11 VSBV-1-positive animals, 9 were from 4 squirrel breeders in Germany (holdings IIV). The remaining 2 were from a private holding in the Netherlands (holding V). Of the 6 variegated squirrels, 3 originated from holding I, where the first VSBV-1-positive 
Table 1. Results of testing for VSBV- in oral swab, blood, and brain samples from squirrels of 4 Sciuridae subfamilies collected in Germany, the Netherlands, and the United Kingdom, 2015*

\begin{tabular}{|c|c|c|c|c|c|c|c|}
\hline \multirow[b]{2}{*}{ Subfamily/species } & \multirow{2}{*}{$\begin{array}{l}\text { No. positive/no. } \\
\text { sampled }\end{array}$} & \multicolumn{6}{|c|}{ Available sample type } \\
\hline & & SS, B, BM & SS, BM & SS, B & $\mathrm{BM}, \mathrm{B}$ & SS & BM \\
\hline \multicolumn{8}{|l|}{ Callosciurinae } \\
\hline Callosciurus erythraeus & $0 / 7$ & 0 & 4 & 2 & 1 & 0 & 0 \\
\hline Callosciurus prevostii & $5 / 57$ & 5 & 0 & 26 & 11 & 14 & 1 \\
\hline Tamiops mcclellandii & $0 / 2$ & 0 & 0 & 2 & 0 & 0 & 0 \\
\hline Tamiops swinhoei & $0 / 4$ & 0 & 0 & 0 & 0 & 4 & 0 \\
\hline \multicolumn{8}{|l|}{ Ratufinae } \\
\hline Ratufa macroura & $0 / 2$ & 0 & 1 & 0 & 0 & 1 & 0 \\
\hline \multicolumn{8}{|l|}{ Sciurinae } \\
\hline Sciurus aureogaster & $0 / 5$ & 0 & 0 & 0 & 0 & 5 & 0 \\
\hline Sciurus carolinensis & $0 / 12$ & 0 & 0 & 0 & 0 & 0 & 12 \\
\hline Sciurus granatensis & $0 / 22$ & 0 & 0 & 4 & 0 & 18 & 0 \\
\hline Sciurus niger & $0 / 2$ & 0 & 0 & 1 & 0 & 1 & 0 \\
\hline Sciurus variegatoides & $7 \dagger / 212$ & 46 & 0 & 63 & 0 & 103 & 0 \\
\hline Sciurus vulgaris & $0 / 127$ & 0 & 2 & 1 & 0 & 62 & 62 \\
\hline \multicolumn{8}{|l|}{ Xerinae } \\
\hline Sciurotamias davidianus & $0 / 9$ & 0 & 1 & 2 & 0 & 6 & 0 \\
\hline Tamias sibiricus & $0 / 1$ & 0 & 0 & 0 & 0 & 1 & 0 \\
\hline Tamias striatus & $0 / 6$ & 0 & 1 & 0 & 0 & 5 & 0 \\
\hline Total & $12 † / 468$ & 51 & 9 & 101 & 12 & 220 & 75 \\
\hline $\begin{array}{l}\text { *Swab samples were taken from } \\
\text { Blood samples (in EDTA or hep } \\
\text { immunofluorescence assay. B, } \\
\text { †lncludes the variegated squirre }\end{array}$ & $\begin{array}{l}\text { ivity of each invest } \\
\text { ver available, wer } \\
\text { orain material; SS, } \\
\text { SBV-1 was initiall }\end{array}$ & $\begin{array}{l}\text { nimal. Oral } \\
\text { by quantitat } \\
\text { ample; VSB } \\
\text { ered (11). }\end{array}$ & $\begin{array}{l}\text { samples } \\
\text { everse tran } \\
\text { variegated }\end{array}$ & $\begin{array}{l}\text { if availak } \\
\text { iption PC } \\
\text { iirrel born }\end{array}$ & $\begin{array}{l}\text { ain samp } \\
\text { vell as by }\end{array}$ & e teste & $\overline{\Gamma-q P C}$ \\
\hline
\end{tabular}

animal was identified in 2014 (11), and the remaining 3 were from holdings II and III. Squirrels from the 3 holdings were traded for breeding. Of the 5 VSBV-1-positive Prevost's squirrels, 3 came from holding IV in Germany, and 2 were from holding $\mathrm{V}$. The positive squirrels in the Netherlands had been transferred from a breeder in Germany in 2011-2012, but we could establish no direct epidemiologic link to the holdings in Germany where we found VSBV-1positive animals.
All animals with detectable virus as well as 40 negative squirrels from the same holdings were euthanized and checked for macroscopic lesions. We applied hematoxylin and eosin staining to formalin-fixed, paraffin-embedded brain sections from 9 of 11 animals and performed immunohistochemistry as described previously (12). A BoDVpositive horse brain sample served as positive control. Histopathology showed that 5 of 9 VSBV-1-positive animals, variegated squirrels as well as Prevost's squirrels, had

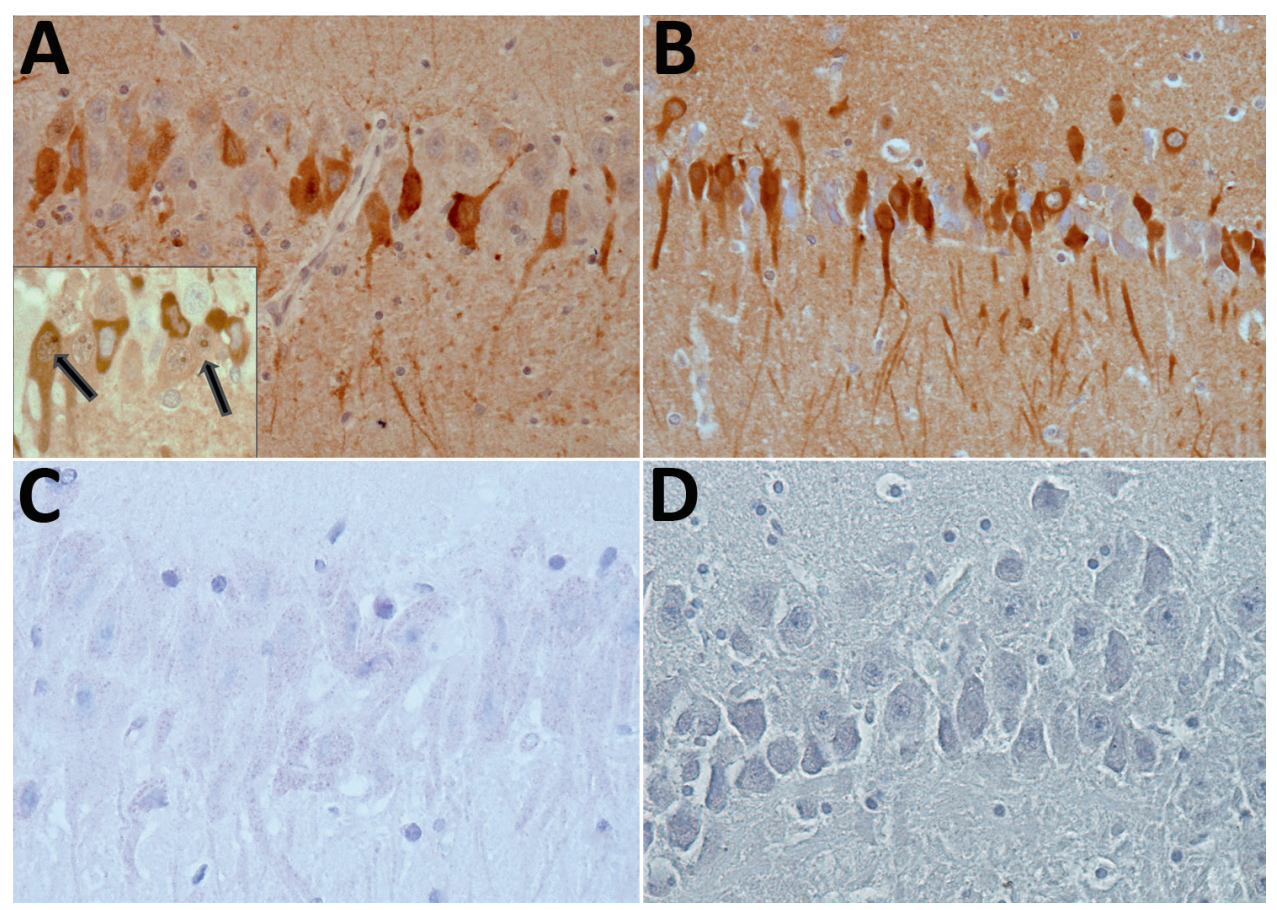

Figure 1. Immunohistochemical detection of bornavirus $X$ protein (A) and phosphoprotein (B) in hippocampal neurons of a brain of a Prevost's squirrel (Callosciurus prevostii) collected in Germany in 2015. Viral antigen is shown in nuclei or cytoplasm and processes. Inset shows intranuclear dot (inclusion body) in cells with and without cytoplasmic immunostaining (arrows). No staining was observed for bornavirus $\mathrm{X}$ protein (C) or phosphoprotein (D) in a bornavirus-negative variegated squirrel. Original magnification $\times 400$. 
Variegated Squirrel Bornavirus 1

Table 2. VSBV-1 RNA levels in samples from squirrels collected in Germany and the Netherlands in 2015 that were positive for viral RNA and VSBV-1 antibodies*

\begin{tabular}{|c|c|c|c|c|c|c|c|c|c|c|c|}
\hline \multirow{3}{*}{$\begin{array}{l}\text { Animal and sample } \\
\text { type }\end{array}$} & \multicolumn{11}{|c|}{ Country and holding no. } \\
\hline & \multicolumn{9}{|c|}{ Germany } & \multicolumn{2}{|c|}{ The Netherlands } \\
\hline & I & I & $\mathrm{I}$ & II & II & III & IV & IV & IV & $\mathrm{V}$ & $\mathrm{V}$ \\
\hline Species & \multicolumn{6}{|c|}{ Sciurus variegatoides } & \multicolumn{5}{|c|}{ Callosciurus prevostii } \\
\hline Identity & $48 / 15-1$ & $48 / 15-2$ & $48 / 15-11$ & $49 / 15-1$ & $49 / 15-6$ & $75 / 15$ & $122 / 15-1$ & $122 / 15-2$ & $133 / 15$ & $3 / 16-1$ & $3 / 16-2$ \\
\hline Animal sex & M & $\mathrm{F}$ & M & M & $\mathrm{F}$ & M & $\mathrm{F}$ & M & M & $\mathrm{F}$ & M \\
\hline EDTA blood/transudate & \pm & \pm & \pm & + & \pm & + & NA & NA & NA & \pm & \pm \\
\hline Oral swab sample & + & \pm & ++ & + & + & + & + & + & + & NA & NA \\
\hline Nose swab sample & \pm & \pm & + & + & \pm & + & + & \pm & \pm & NA & NA \\
\hline Eye swab sample & + & \pm & + & + & \pm & + & NA & \pm & \pm & NA & NA \\
\hline Palatine tonsil & ++ & ++ & ++ & ++ & + & ++ & ++ & ++ & ++ & +++ & ++ \\
\hline $\begin{array}{l}\text { Mesenteric lymph } \\
\text { nodes }\end{array}$ & ++ & ++ & +++ & ++ & ++ & + & ++ & ++ & ++ & + & ++ \\
\hline Brain & +++ & +++ & +++ & +++ & +++ & +++ & ++ & +++ & +++ & +++ & +++ \\
\hline Brachial plexus & ++ & ++ & ++ & ++ & ++ & ++ & ++ & ++ & ++ & + & ++ \\
\hline Medulla oblongata & +++ & +++ & +++ & +++ & +++ & +++ & ++ & ++ & ++ & +++ & +++ \\
\hline Trigeminal ganglion & + & + & +++ & +++ & ++ & ++ & NA & ++ & ++ & ++ & +++ \\
\hline Kidney & ++ & + & ++ & +++ & +++ & ++ & ++ & ++ & ++ & ++ & +++ \\
\hline Salivary gland & ++ & + & + & ++ & ++ & ++ & ++ & ++ & ++ & \pm & +++ \\
\hline Urinary bladder & ++ & ++ & +++ & +++ & ++ & + & ++ & ++ & ++ & ++ & ++ \\
\hline Lung & ++ & ++ & +++ & +++ & ++ & ++ & ++ & + & ++ & \pm & ++ \\
\hline Heart & ++ & + & ++ & ++ & ++ & ++ & + & + & ++ & + & ++ \\
\hline Spleen & + & \pm & ++ & ++ & + & ++ & ++ & ++ & ++ & \pm & +++ \\
\hline Liver & \pm & \pm & + & + & ++ & + & + & + & + & \pm & + \\
\hline Pancreas & ++ & +++ & ++ & ++ & ++ & ++ & ++ & ++ & ++ & + & ++ \\
\hline Sex organ & + & +++ & + & +++ & + & +++ & +++ & ++ & ++ & ++ & +++ \\
\hline Skeletal muscles & + & \pm & + & ++ & + & ++ & ++ & ++ & ++ & + & ++ \\
\hline Skin & ++ & + & ++ & ++ & ++ & ++ & ++ & ++ & ++ & + & ++ \\
\hline Nose cross-section & ++ & ++ & +++ & +++ & ++ & +++ & + & ++ & ++ & ++ & +++ \\
\hline
\end{tabular}

mild nonsuppurative meningitis or encephalitis. In 8 of 9 animals, we also detected intranuclear eosinophilic JoestDegen inclusion bodies in scattered neurons of brain, spinal cord, and trigeminal as well as spinal ganglia (data not shown). We observed bornavirus-specific phosphoprotein and $\mathrm{X}$ protein throughout the brain in neurons, glial cells, and in a few ependymal cells in nuclei, cytoplasm, and cellular processes (Figure 1). We tested a panel of organ samples from all euthanized animals by qRT-PCR. All animals for which swab samples were VSBV-1-positive harbored considerable VSBV-1 genome loads, whereas animals for which swab samples were negative for viral RNA were also negative for viral loads in all tested organs (Table 2; data for control animals not shown). We found the highest viral RNA loads in the CNS and organs (kidney, nose, bladder, salivary gland, and sex organs), which could play a role in viral shedding and transmission (Table 2). Skin sections were also positive, indicating that VSBV-1 has broad cell and organ tropism. We were able to cocultivate infected primary squirrel cells with a permanent cell line and to isolate infectious virus from these passaged cells.

We sequenced the VSBV-1 genome (8,786 nt; missing only the $5^{\prime}$ and $3^{\prime}$ noncoding regions) from all 11 squirrels and compared the sequences with the published VSBV-1 prototype sequence from a variegated squirrel (GenBank accession no. LN713680) (11). Accession numbers of the VSBV-1 sequences from this study are LT 594381LT5943919 (European Nucleotide Archive).

Genomes of viruses detected in squirrels from holding I showed the highest similarity with 1-6 nt substitutions, resulting in 1-3 aa changes, whereas the other sequences exhibited more variability. We found $\leq 29 \mathrm{nt}$ substitutions causing $\leq 19$ aa changes. The mutations were evenly distributed over the coding regions, but in viral genomes of squirrels from the same holding, they often occurred at the same position (Figure 2, panel A).

We aligned the 11 VSBV-1 sequences with those from other bornaviruses by using MAFFT (Multiple Alignment using Fast Fourier Transform), and we used the best-fit model TIM2+I+G4 to construct a phylogenetic tree (IQ-Tree version 1.3.10; http://iqtree.cibiv.univie.ac.at) with 1,000 bootstrap replicates. The novel VSBV-1 genomes clustered with the 2 human- and squirrel-derived prototype sequences LN 713680 and LN71368, forming a unique VSBV-1 clade separate from other mammal, avian, and snake bornaviruses (sequence identity $\leq 69 \%$; Figure 2, panel B).

\section{Conclusions}

We screened 468 squirrels and identified 11 VSBV-1-positive animals, including squirrels belonging to 2 subfamilies 
A

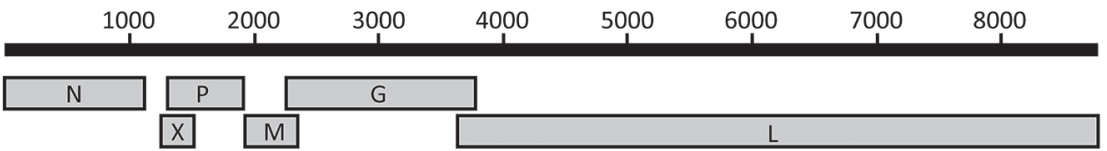

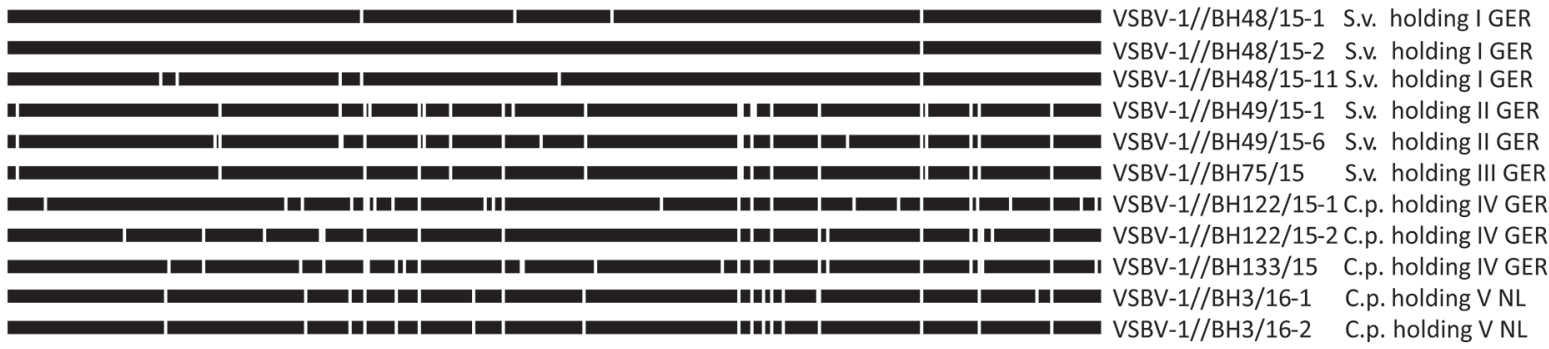

B

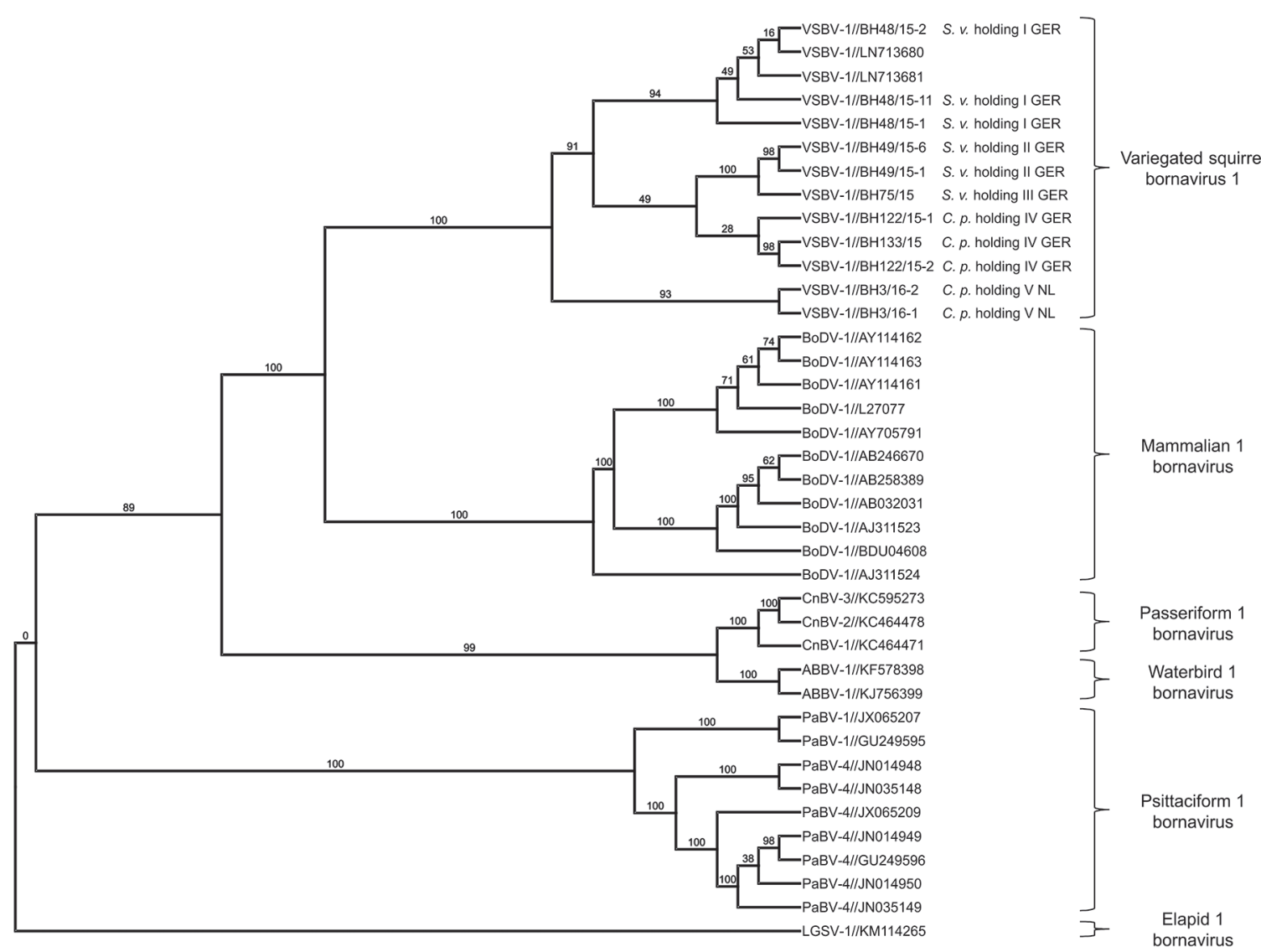

Figure 2. Analysis of 11 newly identified VSBV-1 genomes from squirrels collected in Germany and the Netherlands, 2015, in comparison with related bornaviruses. A) New sequences aligned with published squirrel-derived VSBV-1 genome (GenBank accession no. LN713680). The upper black bar indicates the reference sequence; gray boxes depict the genome. White bar sections for each animal sequence indicate nucleotide variations. The new sequences show 1-29 nucleotide differences compared to the published prototype sequence. G, glycoprotein; L, large structural protein; M, matrix; N, nucleoprotein; P, phosphoprotein; X, nonstructural protein. B) Phylogenetic tree of VSBV-1 isolates from this study (labeled) and comparison sequences. Tree was constructed using the maximum-likelihood method. Numbers along branches are bootstrap values. GER, Germany; NL, the Netherlands; VSBV-1, variegated squirrel bornavirus 1 .

of the family Sciuridae. Although the VSBV-1-positive squirrels originated from different holdings and belonged to different subfamilies, the viral genome sequences formed a distinct VSBV-1 cluster. Whole-genome analyses provided no evidence for specificmutation patterns with regard to zoonotic potential or species-specific adaptations.

None of the VSBV-1-positive animals showed clinical signs of infection. Highest viral genome loads were 
found in the CNS, followed by the oral cavity and skin, indicating the potential for transmission to humans through scratching or biting. Only those squirrels positive for VSBV-1 by qRT-PCR displayed bornavirus-specific antibodies. Although serologic analyses support the qRTPCR results, collecting serum samples is difficult and often not feasible for private breeders. Our data suggest that screening of swab samples is a suitable and reliable tool for noninvasive monitoring of squirrels for VSBV-1 infection. The prevalence of $3.3 \%$ for $S$. variegatoides and $8.8 \%$ for $C$. prevostii squirrels indicates a considerable risk for transmission to humans handling those animals without taking precautionary measures. We therefore recommend routine testing of squirrels in contact with humans, such as those in breeding and holding facilities or zoological gardens, at least from the subfamilies Sciurinae and Callosciurinae.

\section{Acknowledgments}

We thank Christian Korthase, Mareen Lange, Karin Lissek, Susanne Zahnow, Patrick Zitzow, Robert Kohl, Lineke

Begeman, and Stalin Raj for excellent technical assistance. We are grateful to Anna Meredith, Peter Lurz, Sabine Gallenberger, Claudia Bengs, and Stefan Bosch for providing squirrel samples from Germany and the United Kingdom; to Caterina Fiegna, Peter Lurz, Reiner Ulrich, Dörte Kaufmann, Christoph Gertler, and René Ryll for dissection support; and to Jens P. Teifke and Kerstin Tauscher for performing the gross pathology examinations.

The study was funded in part by the EU Horizon 2020 program (European Commission Grant agreement no. 643476 "COMPARE") and contract-research-project MetaInfRisk for the Bundeswehr Medical Service E/U2AD/CF512/DF557. PCR development and screening was also supported by the FriedrichLoeffler-Institut research network "Lyssavirus - a potential public health risk."

Ms. Schlottau is a biologist working on her $\mathrm{PhD}$ thesis at the Institute of Diagnostic Virology, Friedrich-Loeffler-Institut, Insel Riems, Germany. Her research interests include diagnostics of viruses of the Order Mononegavirales and the genetic characterization of lyssaviruses and bornaviruses.

\section{References}

1. Afonso CL, Amarasinghe GK, Bányai K, Bào Y, Basler CF, Bavari S, et al. Taxonomy of the order Mononegavirales: update 2016. Arch Virol. 2016;161:2351-60. http://dx.doi.org/10.1007/ s00705-016-2880-1

2. Bourg M, Herzog S, Encarnação JA, Nobach D, Lange-Herbst H, Eickmann M, et al. Bicolored white-toothed shrews as reservoir for borna disease virus, Bavaria, Germany. Emerg Infect Dis. 2013;19:2064-6. http://dx.doi.org/10.3201/eid1912.131076

3. Hilbe M, Herrsche R, Kolodziejek J, Nowotny N, Zlinszky K, Ehrensperger F. Shrews as reservoir hosts of borna disease virus. Emerg Infect Dis. 2006;12:675-7. http://dx.doi.org/10.3201/ eid1204.051418

4. Dürrwald R, Kolodziejek J, Weissenböck H, Nowotny N. The bicolored white-toothed shrew Crocidura leucodon (HERMANN 1780 ) is an indigenous host of mammalian Borna disease virus. PLoS One. 2014;9:e93659. http://dx.doi.org/10.1371/journal.pone.0093659

5. Nobach D, Bourg M, Herzog S, Lange-Herbst H, Encarnação JA, Eickmann M, et al. Shedding of infectious borna disease virus-1 in living bicolored white-toothed shrews. PLoS One. 2015; 10:e0137018. http://dx.doi.org/10.1371/journal.pone.0137018

6. Hornig M, Briese T, Licinio J, Khabbaz RF, Altshuler LL, Potkin SG, et al. Absence of evidence for bornavirus infection in schizophrenia, bipolar disorder and major depressive disorder. Mol Psychiatry. 2012;17:486-93. http://dx.doi.org/10.1038/mp.2011.179

7. Schwemmle M, Jehle C, Formella S, Staeheli P. Sequence similarities between human bornavirus isolates and laboratory strains question human origin. Lancet. 1999;354:1973-4. http://dx.doi.org/10.1016/S0140-6736(99)04703-0

8. Wolff T, Heins G, Pauli G, Burger R, Kurth R. Failure to detect borna disease virus antigen and RNA in human blood. J Clin Viroly. 2006;36:309-11.

9. Fujino K, Horie M, Honda T, Merriman DK, Tomonaga K. Inhibition of borna disease virus replication by an endogenous bornavirus-like element in the ground squirrel genome. Proc Natl Acad Sci U S A. 2014;111:13175-80. http://dx.doi.org/10.1073/pnas.1407046111

10. Horie M, Honda T, Suzuki Y, Kobayashi Y, Daito T, Oshida T, et al. Endogenous non-retroviral RNA virus elements in mammalian genomes. Nature. 2010;463:84-7. http://dx.doi. org/10.1038/nature08695

11. Hoffmann B, Tappe D, Höper D, Herden C, Boldt A, Mawrin C, et al. A variegated squirrel bornavirus associated with fatal human encephalitis. N Engl J Med. 2015;373:154-62. http://dx.doi.org/10.1056/NEJMoa1415627

12. Piepenbring AK, Enderlein D, Herzog S, Kaleta EF, Heffels-Redmann U, Ressmeyer S, et al. Pathogenesis of avian bornavirus in experimentally infected cockatiels. Emerg Infect Dis. 2012;18:234-41. http://dx.doi.org/10.3201/eid1802.111525

Address for correspondence: Martin Beer, Suedufer 10, 17493

Greifswald-Insel Riems, Germany; email: martin.beer@fli.de 